\title{
Review Article \\ Osteopontin: Relation between Adipose Tissue and Bone Homeostasis
}

\author{
Carolina De Fusco, ${ }^{1}$ Antonietta Messina, ${ }^{1}$ Vincenzo Monda, ${ }^{1}$ \\ Emanuela Viggiano, ${ }^{1,2}$ Fiorenzo Moscatelli, ${ }^{3}$ Anna Valenzano, ${ }^{3}$ Teresa Esposito, ${ }^{1}$ \\ Chieffi Sergio, ${ }^{1}$ Giuseppe Cibelli, ${ }^{3}$ Marcellino Monda, ${ }^{1}$ and Giovanni Messina ${ }^{1,3}$ \\ ${ }^{1}$ Department of Experimental Medicine, Section of Human Physiology and Unit of Dietetic and Sport Medicine, \\ Second University of Naples, 16 Costantinopoli Str., 80138 Naples, Italy \\ ${ }^{2}$ Department of Medicine, University of Padua, Padua, Italy \\ ${ }^{3}$ Department of Clinical and Experimental Medicine, University of Foggia, Foggia, Italy
}

Correspondence should be addressed to Giovanni Messina; gianni.messina@unina2.it

Received 29 April 2016; Revised 19 November 2016; Accepted 18 December 2016; Published 17 January 2017

Academic Editor: Armand Keating

Copyright (C) 2017 Carolina De Fusco et al. This is an open access article distributed under the Creative Commons Attribution License, which permits unrestricted use, distribution, and reproduction in any medium, provided the original work is properly cited.

\begin{abstract}
Osteopontin (OPN) is a multifunctional protein mainly associated with bone metabolism and remodeling. Besides its physiological functions, OPN is implicated in the pathogenesis of a variety of disease states, such as obesity and osteoporosis. Importantly, during the last decades obesity and osteoporosis have become among the main threats to health worldwide. Because OPN is a protein principally expressed in cells with multifaceted effects on bone morphogenesis and remodeling and because it seems to be one of the most overexpressed genes in the adipose tissue of the obese contributing to osteoporosis, this mini review will highlight recent insights about relation between adipose tissue and bone homeostasis.
\end{abstract}

\section{Introduction}

Osteopontin (OPN), also defined as secreted phosphoprotein-1 [1] (SPP1), sialoprotein-1 [1, 2], or early T lymphocyte activation 1 (Eta-1) [3] belongs to the small integrin-binding ligand N-linked glycoprotein (SIBLING) family [4]. SIBLING family consists of noncollagenous proteins (NCPs), primarily involved in bone metabolism and mainly located within the mineralized tissue such as bone and dentin, which also includes bone sialoprotein (BSP (IBSP)), dentin matrix protein 1 (DMP1), dentin sialophosphoprotein (DSPP), and matrix extracellular phosphoglycoprotein (MEPE) $[5,6]$. These soluble secreted glycoproteins undergo posttranslational modifications. They are extensively and heterogeneously spliced, translated, phosphorylated, glycosylated, and proteolysed. These modifications give them bioactive properties [7]. SIBLING proteins exert biological roles in both paracrine and autocrine manner and through multiple functional domains may bind to cell surface integrins [7]. Originally described by Senger in 1979 as a secreted, $60-\mathrm{kDa}$ transformation-specific phosphoprotein [8], human OPN is the most studied component of SIBLING family. It is a Arg-Gly-Asp (RGD) containing multifunctional soluble extracellular matrix-associated glycoprotein of $34 \mathrm{kDa}$ [8] (apparent MW up to $75 \mathrm{kDa}$ ) $[5,6]$. OPN has a gly-arg-glyasp-ser (GRGDS) [9] cell binding domain with $~ 314$ amino acid residues that can regulate cell activities through integrin receptors.

It is encoded by the $S P P 1$ gene, which maps to the long arm of chromosome 4 [6] as a tandem array and generates three splice variants of mRNA, including the isoforms OPN$\mathrm{A}, \mathrm{OPN}-\mathrm{B}$, and OPN-C. OPN-A constitutes the full-length variant [2], whereas isoforms $B$ (missing exon 5) and C (missing exon 4$)$ are the splice variants $[1,2]$. These different forms can display specific expression and have distinct biological roles in different cell contexts. The name "osteopontin" was chosen by Heinegard's group that cloned the protein from the rat osteosarcoma. OPN is produced by cells located in the osteoid matrix, and its name "osteopontin" denotes the property of acting as a bridge ("pons" in Latin) between cells 
and hydroxyapatite of bone $[2,6]$. OPN exists as a secreted (sOPN) and intracellular form (iOPN) [2], being translated from different start codon in the single OPN mRNA.

Intracellular OPN was initially described by Sodek's group in rat calvarial cells $[2,3]$.

Although OPN exists intracellularly as a regulator of cytoskeleton dynamics and gene expression, most studies have focused on the secreted form.

\section{Osteopontin Functions}

OPN is a multifunctional protein widely distributed in many tissues and body fluids, such as plasma, urine, milk, and bile $[10,11]$. It is produced by several cell types, including immune cells like activated macrophages and $\mathrm{T}$ cells, cells of brain and kidney, vascular smooth muscle cells, bone marrow myoblasts, dendritic cells, hepatocytes, and neural cells $[2,6,9]$. Furthermore, OPN is produced by cells involved in bone morphogenesis such as osteoblasts and osteoclasts. OPN regulates various biological activities including matrix remodeling and tissue calcification, monocytes/macrophages migration and chemiotaxis, production of a variety of proinflammatory cytokines and chemokines, and inhibition of apoptosis activities [6]. Furthermore, it is involved in pathophysiological processes as malignancy, insulin resistance and type 2 diabetes, autoimmune disorders, atherosclerosis, steatotic hepatitis, end-stage kidney failure, response to stress, obesity-induced inflammation, and osteoporosis [3, 8]. Recently, numerous researches have examined whether there is a relationship between obesity and osteoporosis. Obesity and osteoporosis are two related polygenic disorders of body composition and represent a major health threat worldwide, with high impact on both morbidity and mortality [12, 13]. Interestingly, an increase of OPN levels in serum and cerebrospinal fluid was found in Alzheimer's disease (AD) patients [14]. AD is a chronic neurodegenerative disease and is the cause of $60 \%$ to $70 \%$ of cases of dementia [15-18]. Conversely, a decrease of OPN levels was associated with the improvement of cognitive functions $[19,20]$.

At bone level, OPN has multifaceted effects on morphogenesis and remodeling $[3,6,13,14]$, being associated with bone turnover and bone mineral density (BMD). Experimental evidence suggests that the gene of OPN is one of the most overexpressed genes in the adipose tissue of obese patients $[1,8]$.

\section{Fat-Bone Relation}

The relationship between obesity and skeleton is complex and not yet fully understood. Body mass index (BMI) is generally recognized to have a good positive correlation with bone mineral density (BMD) as measured by central Dual-Energy X-Ray Absorptiometry (DXA) [21]. For a long time it has been thought that obesity was apparently beneficial for bone metabolism $[22,23]$, particularly in women after menopause, playing a protective effect against the development of bone loss and osteoporosis. Adiposity might ensure bone health probably for the relative hyperestrogenism produced by adipocytes from androgen precursor in postmenopausal women [24-26]. Also the well-established positive effect of mechanical loading (muscle contraction and gravitational loading) related to body weight might positively influence BMD, by decreasing apoptosis and facilitating osteogenic differentiation through the activation of Wnt/b-catenin signaling pathway [27-31]. However, in last decades the view that obesity has an protective effect against osteoporosis has been questioned $[32,33]$. Some reports have shown that excessive visceral fat and fat mass have negative effects on bone health, being associated with low total bone mineral density and content [34-36]. According to these results, another study conducted in healthy premenopausal women demonstrated that central adiposity was associated with low bone quality [37]. Furthermore, it has been suggested that in men and pre- and postmenopausal women fat mass plays a key role in bone health, representing the significant determinant of BMD at the lumbar spine and proximal femur $[19,22]$. Similarly, Greco et al. [38], in a cross-sectional study, evaluated 340 obese women and showed that trunk fat negatively correlated with BMD playing a detrimental role in skeletal metabolism in terms of low BMD, bone markers, and systemic factors influencing bone tissue.

Interestingly, Papakitsou et al. [39] found in obese women a lower rate of bone formation as measured by the serum concentration of type I collagen propeptide, suggesting that obesity can inhibit the production of new collagen. Finally, recent in vitro data supported the hypothesis of decreased osteoblast activity in subjects with increase of trunk mass because of alterations of the Wnt/ $\beta$-catenin pathway [40]. Therefore, obesity and fat accumulation might be detrimental to bone health. However, further investigations are required to better understand the complex pathophysiological relationship between body weight and BMD. Different theories have been proposed to explain the complex interplay between adipose tissue and bone [16, 17]. It has been proposed that the pathophysiological relevance of adipose tissue in bone turnover resides in the participation of three possible mechanisms. (1) There is an intimate link between adipocytes and osteoblasts related to their common origin from a progenitor cell, the pluripotential mesenchymal stem cell (MSCs) that resides in a specialized bone niche [41-43]. As a common precursor, the controlled lineage commitment of MSCs plays an important role in the maintenance of skeleton homeostasis. Osteoblast/adipocyte differentiation, although not mutually exclusive, is intertwined and highly regulated by several cell-derived transcription factors [44] and has been implicated in modification of bone remodeling. For example, recently Yeung et al. [45] have demonstrated that postmenopausal women have more than twice bone marrow fat compared with premenopausal women. (2) Adipose tissue is not only a passive energy reservoir but also an active, complex endocrine organ $[16,17]$ that plays an important role in regulating whole body homeostasis. Adipose tissue secretes various signaling molecules and bioactive compounds, named adipokines (leptin, resistin, IL6, osteopontin, etc.). Adipokines influence bone remodeling (obesity of bone) through upregulated proinflammatory cytokine production and exert an indirect effect on the sympathetic tone via hypothalamic nuclei. Expression 
array studies on human adipose tissue have pointed out an activation of several inflammatory pathways in obesity [46]. In fact, chronic low-grade inflammation is associated with adipose tissue expansion in obesity and it is determined by increased systemic concentrations of proinflammatory endocrine cytokines, such as TNF-alfa [47], and osteopontin $[1,33]$ in patients and animal models of obesity. These cytokines may uncouple bone remodeling by stimulating osteoclast activity or inhibiting bone formation modifying the receptor activator [16]. Thus, all these mechanisms may represent a crosstalk between adipose tissue and skeleton, detrimental for bone health. The exact nature of factor that triggers this mechanisms is unknown.

Osteocalcin is a 49 -amino acid bone matrix noncollagen protein produced by osteoblasts, which is involved in bone deposition and calcium homeostasis. Studies show that osteocalcin also has an important role in energy homeostasis and glucose metabolism: in cross-sectional and prospective epidemiological studies, circulating osteocalcin levels are inversely associated with the risk of type 2 diabetes [48, 49], metabolic syndrome [50,51], overall/abdominal adiposity and insulin resistance [52], and reduced BMD [38].

Furthermore, OC levels were positively associated with cognitive performance in older nondemented women [5356]. Genetic osteocalcin deletion induced glucose intolerance, increased fat mass, insulin resistance, decreased expression of insulin target genes in liver and muscle, and decreased adiponectin gene expression in adipose tissue. In contrast, recombinant osteocalcin administration improved insulin secretion and sensitivity and prevented high-fat-induced obesity and diabetes.

In addition to improving pancreatic insulin secretion, experimental models show that osteocalcin can protect against high-fat-induced obesity, insulin resistance, and nonalcoholic fatty liver disease (NAFLD) [57, 58]. Epidemiological studies are sometimes conflicting and require further validation [59]. Currently the osteocalcin is emerging as an important modulator of energy homeostasis and the metabolism of glucose in various tissues, raising the possibility that this bone-derived hormone may become a new treatment for obesity-related disorders, a hypothesis currently being tested.

\section{Dysregulation of Osteopontin}

In mouse models and obese humans, OPN is one of many inflammatory molecules overexpressed in adipose tissue [60, 61]. Besides, its levels showed a great difference in adipose tissue between monozygotic twins discordant for obesity condition [62]. Its overexpression in obese adipose tissue is mainly attributable to accumulation of the macrophages [1] and other inflammatory cells, stromal vascular cells, and adipocytes. Nomiyama et al. [63] suggested that OPN might be involved in linking obesity-induced inflammatory processes and metabolic changes in adipose tissue. Similarly, it has described a high level of OPN RNA expression in adipose tissue of obese insulin resistant rats and humans [8]. Kiefer and colleagues [1] showed that obesity is associated with a striking increase of OPN expression selectively within adipose tissue. Adipose tissues are the major source of OPN and also of its obesity-induced upregulation. These data point toward a specific pathophysiological role of OPN in obesity. Therefore, OPN could be a key regulator of inflammatory processes linked to obesity-induced adipose tissue inflammation and become a major target for treatment of adipose tissue inflammation-related disorders. Recently, it has been shown that genetic OPN deficiency and antibodymediated neutralisation in mice improve inflammation and protect from obesity and insulin resistance induced by a highfat diet [46]. OPN would act as proinflammatory cytokine and have pleiotropic function in inflammation. The primary role of OPN seems to facilitate recovery of the organism after injury or infection [38]. However, several studies have highlighted the critical role of OPN in regulating not only adipose tissue inflammation, but also insulin resistance and diabetes mellitus [64, 65].

Recently, an alteration of adipose tissue function has been related to various human metabolism disorders such as osteoporosis [66]. It has been suggested that OPN influences adipogenic process, in bone marrow of obese womencontributing to the development of osteoporosis. An imbalance has been described between normal adipogenesis and osteogenesis of MSCs, prevailing adipocyte differentiation on osteoblast differentiation [67]. MSCs isolated from bone marrow in postmenopausal patients with osteoporosis express more adipocytic differentiation markers than those in women with normal bone mass [68]. Meunier et al. [69] analyzed 81 iliac crest biopsies from elderly women and observed a considerable amount of fat in bone marrow of women with osteoporosis, relative to levels of fat in healthy young women. This observation was confirmed in subsequent studies [7072]. An increment of marrow adipocytes was observed also by Schellinger et al. [73]. After oophorectomy, rats showed an increase in the amount of fat in the bone marrow [17]. Fat infiltration might considerate a typical example of lipotoxicity. Triggiani and colleagues [30], too, have observed similar results.

Many researchers considered osteoporosis as a faultiness of bone marrow MSCs [74] in differentiating into other cell lineages, with adipogenesis being enhanced compared to osteoblastogenesis. Molecular mechanisms of adipocyte differentiation have been studied using both in vitro and in vivo models but the cellular and molecular mechanisms mediating the pathological switch in fat remain to be determined [39]. What is the player of the fat-bone axis in the bone marrow? Because OPN-/- mice could be due to changes in the balance between osteogenic and adipogenic differentiation by MSCs [3], we want to know the role of OPN in MSCs differentiation. Further studies are needed to define the precise relationship between obesity and osteoporosis. Previous studies have shown that, in overweight and obese humans, the dysregulation of circulating signaling factors, such as inflammatory cytokines, might play an important role in changes of MSC differentiation [75-78]. Among cytokines, OPN may represent a multifaceted regulator between fat and bone on bone remodeling and contribute to the development of osteoporosis [3]. In the study conducted by Inoue and Shinohara [3] on the effects of secreted OPN in regulating MSC 
differentiation, the authors revealed an important role of OPN-integrin $\alpha v / \beta 1$ in regulating adipogenic and osteogenic differentiation. Di Bernardo et al. [78] in their study in vitro observed that the incubation of MSCs with the sera of overweight individuals promoted a bias in differentiating MSCs in adipogenic line, probably for a modification of circulating cytokines. OPN by itself induces expression of a variety of proinflammatory cytokines and chemokines being an important regulator for initiating adipose tissue macrophage and macrophage-like cells infiltration, triggering a vicious circle in which inflammatory cytokines play important roles in MSC differentiation. Moreover, other studies are required to elucidate the precise role of OPN in the pathophysiology of osteoporosis and as a possible crucial link of bone-adipose axis.

\section{Conclusion}

OPN was identified in 1980; it is a key regulator of many metabolic and inflammatory diseases, such as diabetes, cardiovascular disease, and obesity. Some studies have shown that OPN is causally involved in the pathogenesis of insulin resistance and type 2 diabetes, while other studies have shown that OPN is a protective islet protein preserving insulin secretion. In addition, experimental and epidemiological evidence emerging disclosed complex cytokine and hormonal crosstalk between bone cells, liver, and adipose tissue, which adjusts coordinated bone remodeling, energy metabolism, and glucose homeostasis; changes in this network may contribute to the pathogenesis of obesity and related disorders [58], but some key questions have not yet been resolved. Therefore, further research will clarify the clinical significance of these changes that cause metabolic and inflammatory diseases, and they will identify individuals at higher risk for developing such complications and for therapeutic purposes.

\section{Disclosure}

Carolina De Fusco and Antonietta Messina are first authors.

\section{Competing Interests}

The authors declare that they have no competing interests.

\section{References}

[1] F. W. Kiefer, M. Zeyda, J. Todoric et al., "Osteopontin expression in human and murine obesity: extensive local up-regulation in adipose tissue but minimal systemic alterations," Endocrinology, vol. 149, no. 3, pp. 1350-1357, 2008.

[2] Y. Wen, S. Jeong, Q. Xia, and X. Kong, "Role of osteopontin in liver diseases," International Journal of Biological Sciences, vol. 12, no. 9, pp. 1121-1128, 2016.

[3] M. Inoue and M. L. Shinohara, "Intracellular osteopontin (iOPN) and immunity," Immunologic Research, vol. 49, no. 1-3, pp. 160-172, 2011.

[4] Q. Chen, P. Shou, L. Zhang et al., "An osteopontin-integrin interaction plays a critical role in directing adipogenesis and osteogenesis by mesenchymal stem cells," Stem Cells, vol. 32, no. 2, pp. 327-337, 2014.
[5] K. A. Staines, V. E. MacRae, and C. Farquharson, "The importance of the SIBLING family of proteins on skeletal mineralisation and bone remodelling," Journal of Endocrinology, vol. 214, no. 3, pp. 241-255, 2012.

[6] A. N. Kothari, M. L. Arffa, V. Chang et al., "Osteopontin-a master regulator of epithelial-mesenchymal transition," Journal of Clinical Medicine, vol. 5, no. 4, p. 39, 2016.

[7] T. E. Kruger, A. H. Miller, A. K. Godwin, and J. Wang, "Bone sialoprotein and osteopontin in bone metastasis of osteotropic cancers," Critical Reviews in Oncology/Hematology, vol. 89, no. 2, pp. 330-341, 2014.

[8] A. Oldberg, A. Franzen, and D. Heinegard, "Cloning and sequence analysis of rat bone sialoprotein (osteopontin) cDNA reveals an Arg-Gly-Asp cell-binding sequence," Proceedings of the National Academy of Sciences of the United States of America, vol. 83, no. 23, pp. 8819-8823, 1986.

[9] J. Sodek, B. Ganss, and M. McKee, “Osteopontin,” Critical Reviews in Oral Biology \& Medicine, vol. 11, no. 3, pp. 279-303, 2000.

[10] J. Chapman, P. D. Miles, J. M. Ofrecio et al., "Osteopontin is required for the early onset of high fat diet-induced insulin resistance in mice," PLoS ONE, vol. 5, no. 11, Article ID e13959, 2010.

[11] F. W. Kiefer, S. Neschen, B. Pfau et al., "Osteopontin deficiency protects against obesity-induced hepatic steatosis and attenuates glucose production in mice," Diabetologia, vol. 54, no. 8, pp. 2132-2142, 2011.

[12] C. J. Rosen and M. L. Bouxsein, "Mechanisms of disease: is osteoporosis the obesity of bone?" Nature Clinical Practice Rheumatology, vol. 2, no. 1, pp. 35-43, 2006.

[13] S. Rössner, "Obesity: the disease of the twenty-first century," International Journal of Obesity, vol. 26, no. S4, pp. S2-S4, 2002.

[14] C. Comi, M. Carecchio, A. Chiocchetti et al., "Osteopontin is increased in the cerebrospinal fluid of patients with Alzheimer's disease and its levels correlate with cognitive decline," Journal of Alzheimer's Disease, vol. 19, no. 4, pp. 1143-1148, 2010.

[15] C. Aurilio, M. C. Pace, M. B. Passavanti et al., "Chronic pain pharmacological treatment in patients with depressive disorders," African Journal of Psychiatry, vol. 18, article 307, 2015.

[16] A. Burns and S. Iliffe, "Alzheimer's disease," BMJ, vol. 338, p. b158, 2009.

[17] S. Chieffi, C. Secchi, and M. Gentilucci, "Deictic word and gesture production: their interaction," Behavioural Brain Research, vol. 203, no. 2, pp. 200-206, 2009.

[18] A. Iavarone, M. Patruno, F. Galeone, S. Chieffi, and S. Carlomagno, "Brief report: error pattern in an autistic savant calendar calculator," Journal of Autism and Developmental Disorders, vol. 37, no. 4, pp. 775-779, 2007.

[19] P. Iaffaldano, M. Ruggieri, R. G. Viterbo, M. Mastrapasqua, and M. Trojano, "The improvement of cognitive functions is associated with a decrease of plasma Osteopontin levels in Natalizumab treated relapsing multiple sclerosis," Brain, Behavior, and Immunity, vol. 35, pp. 96-101, 2014.

[20] S. Chieffi, M. Conson, and S. Carlomagno, "Movement velocity effects on kinaesthetic localisation of spatial positions," Experimental Brain Research, vol. 158, no. 4, pp. 421-426, 2004.

[21] C. Poiana, M. Carsote, V. Radoi, A. Mihai, and C. Capatina, "Prevalent osteoporotic fractures in 622 obese and non- obese menopausal women," Journal of medicine and life, vol. 8 , no. 4, pp. 462-466, 2015. 
[22] M. Monda, G. Messina, I. Scognamiglio et al., "Short-term diet and moderate exercise in young overweight men modulate cardiocyte and hepatocarcinoma survival by oxidative stress," Oxidative Medicine and Cellular Longevity, vol. 2014, Article ID 131024, 7 pages, 2014.

[23] E. A. Greco, A. Lenzi, and S. Migliaccio, "The obesity of bone," Therapeutic Advances in Endocrinology and Metabolism, vol. 6, no. 6, pp. 273-286, 2015.

[24] L. Guo, X. Yang, H. Zhu et al., "Sertoli-Leydig cell tumor presenting hyperestrogenism in a postmenopausal woman: a case report and review of the literature," Taiwanese Journal of Obstetrics and Gynecology, vol. 51, no. 4, pp. 620-624, 2012.

[25] V. Monda, A. Valenzano, F. Moscatelli et al., "Modifications of activity of autonomic nervous system, and resting energy expenditure in women using hormone-replacement therapy," Biology and Medicine, vol. 8, no. 5, article no. 306, 2016.

[26] G. Messina, V. Monda, F. Moscatelli et al., "Role of orexin system in obesity," Biology and Medicine, vol. 7, Article ID 1000248, 2015.

[27] K. Hayashida, Y. Takeda, H. Yatake et al., "Relationship between bone mineral density and body composition estimated by dualenergy $\mathrm{x}$-ray absorptiometry: comparison between groups aged 20-39 and 40-59 years," Kobe Journal of Medical Sciences, vol. 61, no. 4, pp. E97-E101, 2015.

[28] J. Menzel, R. di Giuseppe, A. Wientzek, A. Kroke, H. Boeing, and C. Weikert, "Physical activity, bone health, and obesity in Peri-/Pre- and postmenopausal women: results from the EPICpotsdam study," Calcified Tissue International, vol. 97, no. 4, pp. 376-384, 2015.

[29] D. Gatti, O. Viapiana, L. Idolazzi et al., "Distinct effect of zoledronate and clodronate on circulating levels of DKK1 and sclerostin in women with postmenopausal osteoporosis," Bone, vol. 67, pp. 189-192, 2014.

[30] A. I. Triggiani, A. Valenzano, M. A. P. Ciliberti et al., "Heart rate variability is reduced in underweight and overweight healthy adult women," Clinical Physiology and Functional Imaging, 2015.

[31] F. Moscatelli, G. Messina, A. Valenzano et al., "Differences in corticospinal system activity and reaction response between karate athletes and non-athletes," Neurological Sciences, vol. 37, no. 12, pp. 1947-1953, 2016.

[32] S. Migliaccio, E. A. Greco, R. Fornari, L. M. Donini, and A. Lenzi, "Is obesity in women protective against osteoporosis?" Diabetes, Metabolic Syndrome and Obesity: Targets and Therapy, vol. 4, pp. 273-282, 2011.

[33] K. Zhu, M. Hunter, A. James, E. M. Lim, and J. P. Walsh, "Associations between body mass index, lean and fat body mass and bone mineral density in middle-aged Australians: the Busselton Healthy Ageing Study," Bone, vol. 74, pp. 146-152, 2015.

[34] M. Monda, G. Messina, C. Mangoni, and B. De Luca, "Resting energy expenditure and fat-free mass do not decline during aging in severely obese women," Clinical Nutrition, vol. 27, no. 4, pp. 657-659, 2008.

[35] G. Messina, A. Viggiano, D. Tafuri et al., "Role of orexin in obese patients in the intensive care unit," Journal of Anesthesia and Clinical Research, vol. 5, no. 3, Article ID 1000395, 2014.

[36] K.-C. Kim, D.-H. Shin, S.-Y. Lee, J.-A. Im, and D.-C. Lee, "Relation between obesity and bone mineral density and vertebral fractures in Korean postmenopausal women," Yonsei Medical Journal, vol. 51, no. 6, pp. 857-863, 2010.

[37] A. Cohen, D. W. Dempster, R. R. Recker et al., "Abdominal fat is associated with lower bone formation and inferior bone quality in healthy premenopausal women: a transiliac bone biopsy study," Journal of Clinical Endocrinology and Metabolism, vol. 98, no. 6, pp. 2562-2572, 2013.

[38] E. A. Greco, D. Francomano, R. Fornari et al., "Negative association between trunk fat, insulin resistance and skeleton in obese women," World Journal of Diabetes, vol. 4, no. 2, pp. 31-39, 2013.

[39] E. F. Papakitsou, A. N. Margioris, K. E. Dretakis et al., "Body mass index (BMI) and parameters of bone formation and resorption in postmenopausal women," Maturitas, vol. 47, no. 3, pp. 185-193, 2004.

[40] F. Wannenes, V. Papa, E. A. Greco et al., "Abdominal fat and sarcopenia in women significantly alter osteoblasts homeostasis in vitro by a $\mathrm{WNT} / \beta$-catenin dependent mechanism," International Journal of Endocrinology, vol. 2014, Article ID 278316, 10 pages, 2014.

[41] L. da Silva Meirelles, P. C. Chagastelles, and N. B. Nardi, "Mesenchymal stem cells reside in virtually all post-natal organs and tissues," Journal of Cell Science, vol. 119, no. 11, pp. 22042213, 2006.

[42] T. Akune, S. Ohba, S. Kamekura et al., "PPAR $\gamma$ insufficiency enhances osteogenesis through osteoblast formation from bone marrow progenitors," Journal of Clinical Investigation, vol. 113, no. 6, pp. 846-855, 2004.

[43] C. M. Digirolamo, D. Stokes, D. Colter, D. G. Phinney, R. Class, and D. J. Prockop, "Propagation and senescence of human marrow stromal cells in culture: a simple colony-forming assay identifies samples with the greatest potential to propagate and differentiate," British Journal of Haematology, vol. 107, no. 2, pp. 275-281, 1999.

[44] T. Takahashi, "Overexpression of Runx2 and MKP-1 stimulates transdifferentiation of 3T3-L1 preadipocytes into bone-forming osteoblasts in vitro," Calcified Tissue International, vol. 88, no. 4, pp. 336-347, 2011.

[45] D. K. W. Yeung, J. F. Griffith, G. E. Antonio, F. K. H. Lee, J. Woo, and P. C. Leung, "Osteoporosis is associated with increased marrow fat content and decreased marrow fat unsaturation: a proton MR spectroscopy study," Journal of Magnetic Resonance Imaging, vol. 22, no. 2, pp. 279-285, 2005.

[46] S. Nair, Y. H. Lee, E. Rousseau et al., "Increased expression of inflammation-related genes in cultured preadipocytes/stromal vascular cells from obese compared with non-obese Pima Indians," Diabetologia, vol. 48, no. 9, pp. 1784-1788, 2005.

[47] G. S. Hotamisligil, N. S. Shargill, and B. M. Spiegelman, "Adipose expression of tumor necrosis factor- $\alpha$ : direct role in obesity-linked insulin resistance," Science, vol. 259, no. 5091, pp. 87-91, 1993.

[48] A. Movahed, B. Larijani, I. Nabipour et al., "Reduced serum osteocalcin concentrations are associated with type 2 diabetes mellitus and the metabolic syndrome components in postmenopausal women: the crosstalk between bone and energy metabolism," Journal of Bone and Mineral Metabolism, vol. 30, no. 6, pp. 683-691, 2012.

[49] C. Ngarmukos, L.-O. Chailurkit, S. Chanprasertyothin, B. Hengprasith, P. Sritara, and B. Ongphiphadhanakul, "A reduced serum level of total osteocalcin in men predicts the development of diabetes in a long-term follow-up cohort," Clinical Endocrinology, vol. 77, no. 1, pp. 42-46, 2012.

[50] M. M. Oosterwerff, N. M. Van Schoor, P. Lips, and E. M. W. Eekhoff, "Osteocalcin as a predictor of the metabolic syndrome in older persons: a population-based study," Clinical Endocrinology, vol. 78, no. 2, pp. 242-247, 2013. 
[51] K. B. D. S. Magalhães, M. M. Magalhães, E. T. Diniz, C. S. Lucena, L. Griz, and F. Bandeira, "Metabolic syndrome and central fat distribution are related to lower serum osteocalcin concentrations," Annals of Nutrition and Metabolism, vol. 62, no. 3, pp. 183-188, 2013.

[52] Y. Bao, M. Xiaojing, R. Yang et al., "Inverse relationship between serum osteocalcin levels and visceral fat area in Chinese men," Journal of Clinical Endocrinology and Metabolism, vol. 98, no. 1, pp. 345-351, 2013.

[53] S. Bradburn, J. S. McPhee, L. Bagley et al., "Association between osteocalcin and cognitive performance in healthy older adults," Age and Ageing, vol. 45, no. 6, pp. 844-849, 2016.

[54] S. Chieffi, A. Iavarone, A. Viggiano, M. Monda, and S. Carlomagno, "Effect of a visual distractor on line bisection," Experimental Brain Research, vol. 219, no. 4, pp. 489-498, 2012.

[55] S. Chieffi, T. Iachini, A. Iavarone, G. Messina, A. Viggiano, and M. Monda, "Flanker interference effects in a line bisection task," Experimental Brain Research, vol. 232, no. 4, pp. 1327-1334, 2014.

[56] A. Viggiano, S. Chieffi, D. Tafuri, G. Messina, M. Monda, and B. De Luca, "Laterality of a second player position affects lateral deviation of basketball shooting," Journal of Sports Sciences, vol. 32, no. 1, pp. 46-52, 2014.

[57] A. Kode, I. Mosialou, B. C. Silva et al., "FoxO1 protein cooperates with ATF4 protein in osteoblasts to control glucose homeostasis," The Journal of Biological Chemistry, vol. 287, no. 12, pp. 8757-8768, 2012.

[58] G. Musso, E. Paschetta, R. Gambino, M. Cassader, and F. Molinaro, "Interactions among bone, liver, and adipose tissue predisposing to diabesity and fatty liver," Trends in Molecular Medicine, vol. 19, no. 9, pp. 522-535, 2013.

[59] N. Abseyi, Z. Şiklar, M. Berberoğlu, B. Hacihamdioğlu, Ş. S. Erdeve, and G. Öçal, "Relationships between osteocalcin, glucose metabolism, and adiponectin in obese children: is there crosstalk between bone tissue and glucose metabolism?" JCRPE Journal of Clinical Research in Pediatric Endocrinology, vol. 4, no. 4, pp. 182-188, 2012.

[60] D. D. Sears, G. Hsiao, A. Hsiao et al., "Mechanisms of human insulin resistance and thiazolidinedione-mediated insulin sensitization," Proceedings of the National Academy of Sciences of the United States of America, vol. 106, no. 44, pp. 18745-18750, 2009.

[61] H. Xu, G. T. Barnes, Q. Yang et al., "Chronic inflammation in fat plays a crucial role in the development of obesity-related insulin resistance," The Journal of Clinical Investigation, vol. 112, no. 12, pp. 1821-1830, 2003.

[62] K. H. Pietiläinen, J. Naukkarinen, A. Rissanen et al., "Global transcript profiles of fat in monozygotic twins discordant for BMI: pathways behind acquired obesity," PLoS Medicine, vol. 5, no. 3, pp. 472-483, 2008.

[63] T. Nomiyama, D. Perez-Tilve, D. Ogawa et al., "Osteopontin mediates obesity-induced adipose tissue macrophage infiltration and insulin resistance in mice," The Journal of Clinical Investigation, vol. 117, no. 10, pp. 2877-2888, 2007.

[64] F. J. A. de Paula, M. C. Horowitz, and C. J. Rosen, "Novel insights into the relationship between diabetes and osteoporosis," Diabetes/Metabolism Research and Reviews, vol. 26, no. 8, pp. 622630, 2010.

[65] F. W. Kiefer, M. Zeyda, K. Gollinger et al., "Neutralization of osteopontin inhibits obesity-induced inflammation and insulin resistance," Diabetes, vol. 59, no. 4, pp. 935-946, 2010.

[66] M. Kawai, F. J. A. de Paula, and C. J. Rosen, "New insights into osteoporosis: the bone-fat connection," Journal of Internal Medicine, vol. 272, no. 4, pp. 317-329, 2012.
[67] J. P. Rodrguez, L. Montecinos, S. Ros, P. Reyes, and J. Martnez, "Mesenchymal stem cells from osteoporotic patients produce a type I collagen-deficient extracellular matrix favoring adipogenic differentiation," Journal of Cellular Biochemistry, vol. 79, no. 4, pp. 557-565, 2000.

[68] I. Sekiya, B. L. Larson, J. T. Vuoristo, J.-G. Cui, and D. J. Prockop, "Adipogenic differentiation of human adult stem cells from bone marrow stroma (MSCs)," Journal of Bone and Mineral Research, vol. 19, no. 2, pp. 256-264, 2004.

[69] P. Meunier, J. Aaron, C. Edouard, and G. Vignon, “Osteoporosis and the replacement of cell populations of the marrow by adipose tissue. A quantitative study of 84 iliac bone biopsies," Clinical Orthopaedics and Related Research, vol. 80, pp. 147-154, 1971.

[70] C. Rozman, E. Feliu, L. Berga, J.-C. Reverter, C. Climent, and M.-J. Ferrán, "Age-related variations of fat tissue fraction in normal human bone marrow depend both on size and number of adipocytes: a stereological study," Experimental Hematology, vol. 17, no. 1, pp. 34-37, 1989.

[71] G. Messina, C. Vicidomini, A. Viggiano et al., "Enhanced parasympathetic activity of sportive women is paradoxically associated to enhanced resting energy expenditure," Autonomic Neuroscience: Basic and Clinical, vol. 169, no. 2, pp. 102-106, 2012.

[72] S. Verma, J. H. Rajaratnam, J. Denton, J. A. Hoyland, and R. J. Byers, "Adipocytic proportion of bone marrow is inversely related to bone formation in osteoporosis," Journal of Clinical Pathology, vol. 55, no. 9, pp. 693-698, 2002.

[73] D. Schellinger, Chin Shoou Lin, H. G. Hatipoglu, and D. Fertikh, "Potential value of vertebral proton MR spectroscopy in determining bone weakness," American Journal of Neuroradiology, vol. 22, no. 8, pp. 1620-1627, 2001.

[74] B. Gao, L. Yang, and Z.-J. Luo, "Transdifferentiation between bone and fat on bone metabolism," International Journal of Clinical and Experimental Pathology, vol. 7, no. 5, pp. 1834-1841, 2014.

[75] M. Esposito, F. P. Serpe, G. Diletti et al., "Serum levels of polychlorinated dibenzo-p-dioxins, polychlorinated dibenzofurans and polychlorinated biphenyls in a population living in the Naples area, southern Italy," Chemosphere, vol. 94, pp. 62-69, 2014.

[76] A. Viggiano, U. Nicodemo, E. Viggiano et al., "Mastication overload causes an increase in O2- production into the subnucleus oralis of the spinal trigeminal nucleus," Neuroscience, vol. 166, no. 2, pp. 416-421, 2010.

[77] B. Rinaldi, F. Guida, A. Furiano et al., "Effect of prolonged moderate exercise on the changes of nonneuronal cells in early myocardial infarction," Neural Plasticity, vol. 2015, Article ID 265967, 8 pages, 2015.

[78] G. Di Bernardo, G. Messina, S. Capasso et al., "Sera of overweight people promote in vitro adipocyte differentiation of bone marrow stromal cells," Stem Cell Research and Therapy, vol. 5, no. 1, article 4, 2014 . 

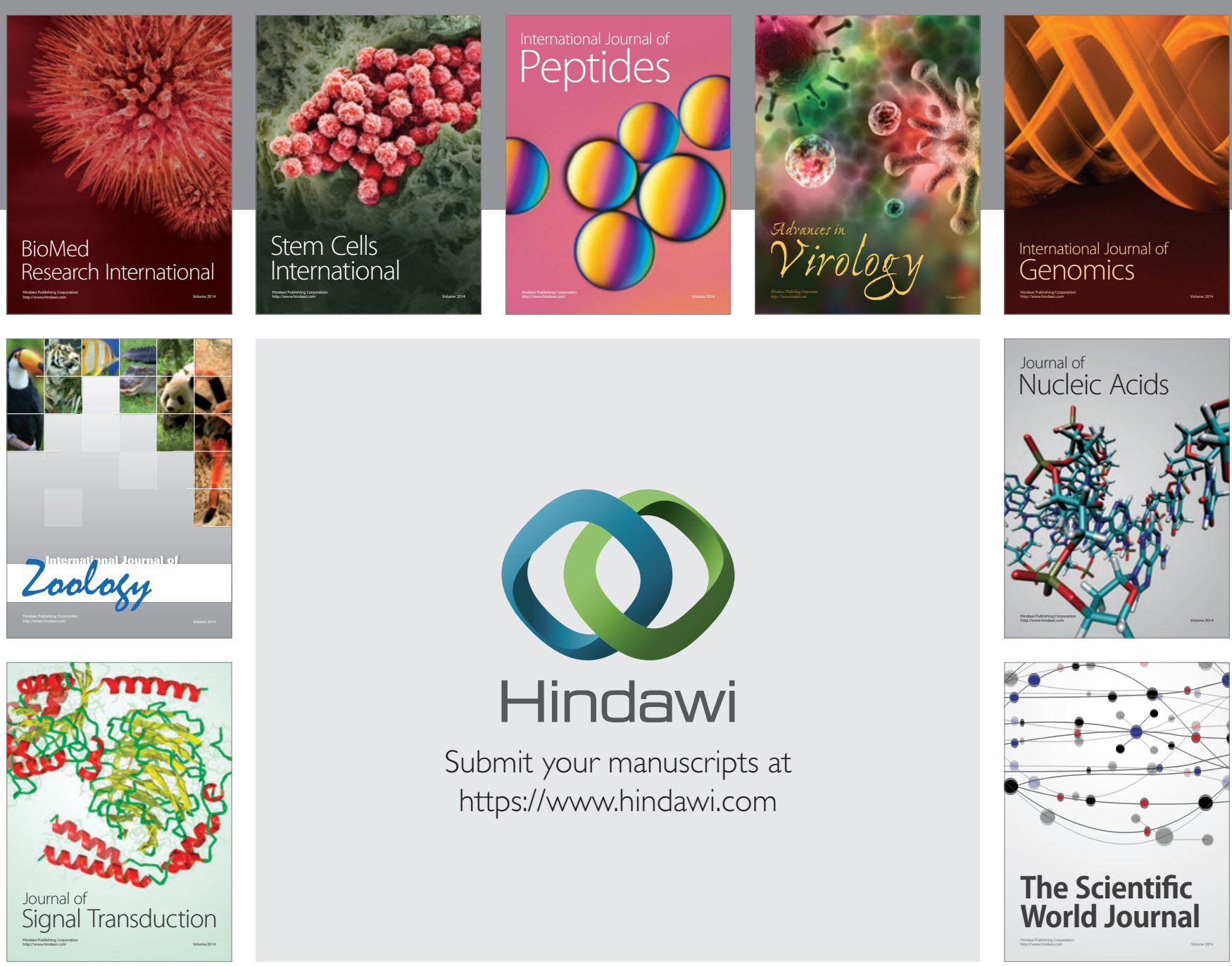

Submit your manuscripts at

https://www.hindawi.com
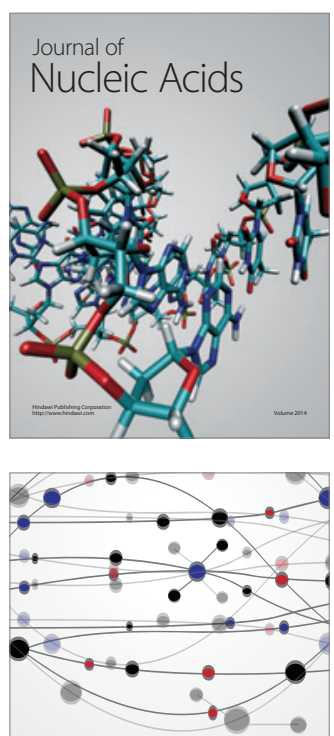

The Scientific World Journal
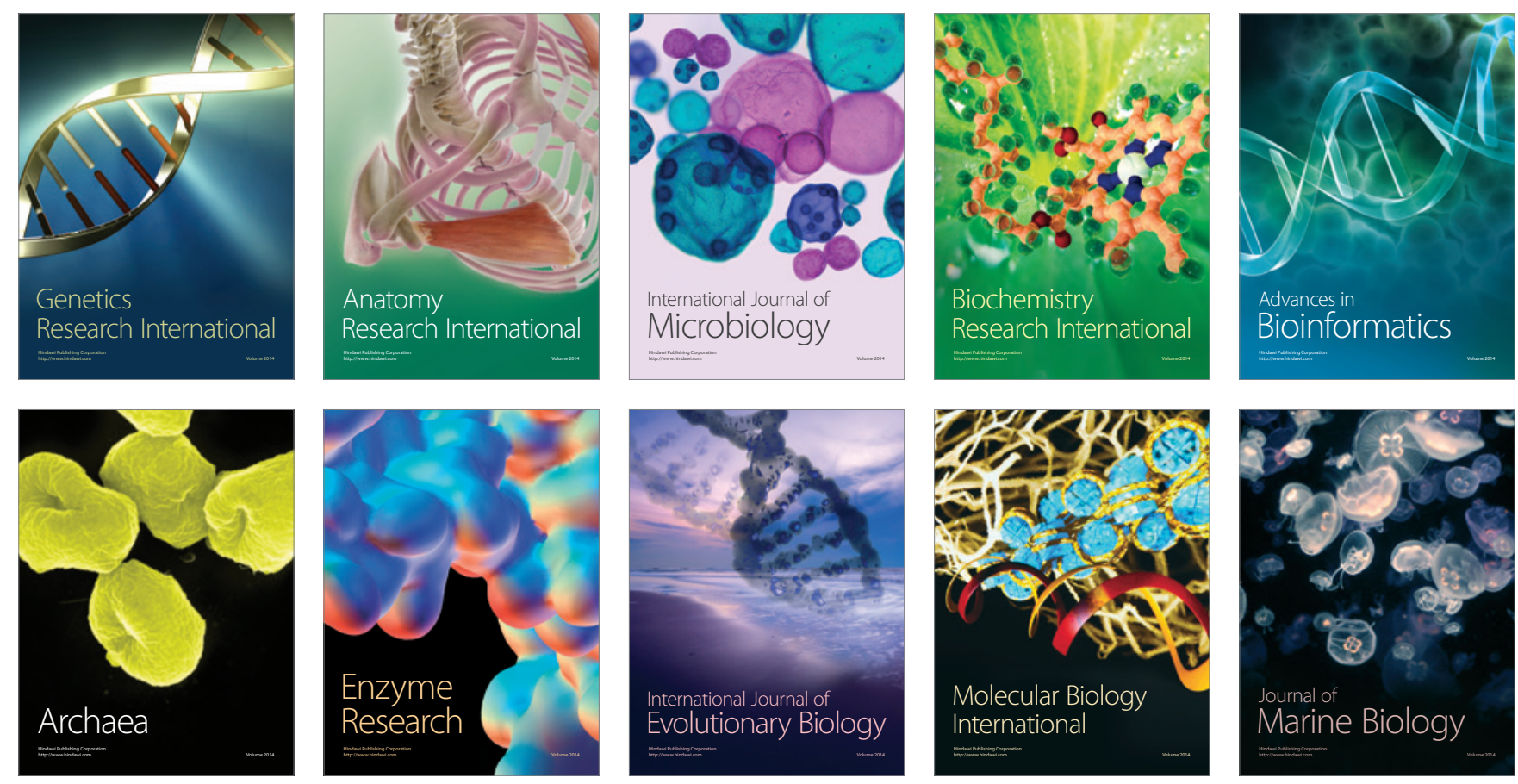